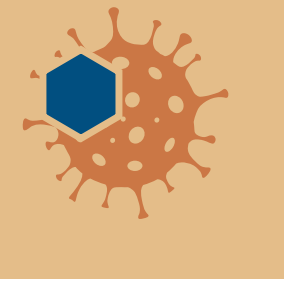

\title{
The COVID-19 pandemic informs future directions of US research universities
}

"I remember first hearing this term 'digital divide' in the mid-1990s. It was the concept of people from lower socioeconomic status not having access to computers and the Internet," says Tabbetha Dobbins, the Interim Vice President for Research and Dean of the Graduate School at Rowan University in New Jersey, in an interview with MRS Bulletin. "It has always been talked about in a scope of, well, there will be jobs available to people who have these computer skills; and people who don't, won't be seeing those jobs."

Dobbins recently participated in a webinar training $\mathrm{K}-12$ teachers on diversity, equity, and inclusion where she learned that some students have trouble transitioning to online learning during the pandemic because their families cannot afford a computer and access to the
Internet. They are, therefore, locked out of an education. "[The Internet] is at least a \$70-\$80 bill per month and some families simply can't sustain that," she says. Looking toward US research universities of the 21st century, Dobbins says, "By taking our eye off of that ball 25 years ago and not fixing the problem, how far have we disadvantaged students into pursuing computational materials studies who come from low socioeconomic grounds?"

"I think that every department should take an assessment of whether their students have access to the resources they need in order to go back offline again. And if they know three or four students in a materials science department, for example, who might fall into that category, to try to come up with solutions," Dobbins told MRS Bulletin.

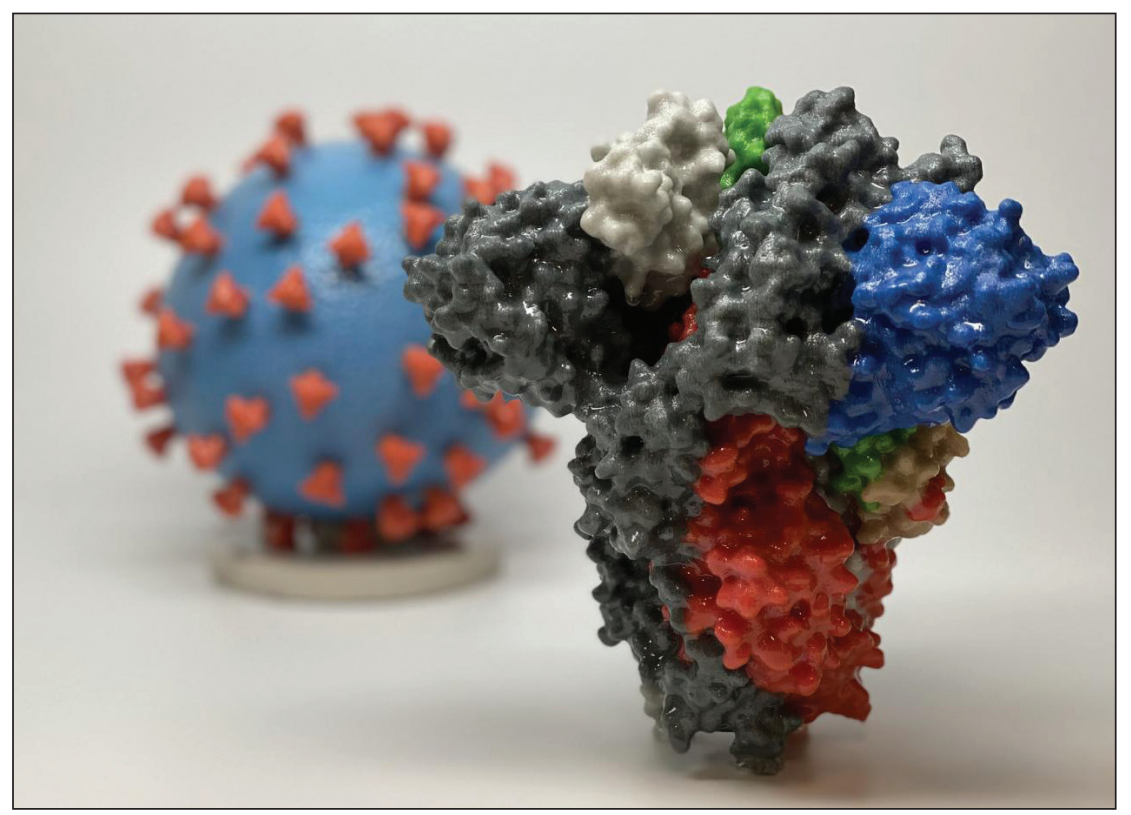

3D print of a spike protein of SARS-CoV-2, the virus that causes COVID-19-in front of a 3D print of a SARS-CoV-2 virus particle. The spike protein (foreground) enables the virus to enter and infect human cells. On the virus model, the virus surface (blue) is covered with the spike proteins (red). For more information, visit the NIH 3D Print Exchange at 3dprint.nih.gov. Credit: NIH.

On the 75th anniversary of Vannevar Bush's report that shaped science policy in the United States, the US National Academy of Sciences (NAS) is exploring systemic changes that need to be made to set science policy for the next 75 years. NAS began the discussion at a Symposium held in February 2020 (MRS Bulletin doi:10.1557/mrs.2020.154). At a subsequent Workshop, held in July, NAS has focused on US research universities. The onset of the novel coronavirus pandemic, says Marcia McNutt, president of NAS, has illuminated the strengths of universities to change their processes overnight "and also illuminated challenges our universities face."

The Workshop, titled "Reopening US Research Universities: Confronting Long-Standing Challenges and Imagining Novel Solutions," has brought together academics and representatives from scientific and government organizations to envision a paradigm shift in research universities. It was hosted by the Committee on Science, Engineering, Medicine and Public Policy (COSEMPUP) within the National Academies of Sciences, Engineering, and Medicine on July 21.

On a positive note, in the area of R\&D, McNutt says the pandemic has driven an "unprecedented level of international collaboration and cooperation" and has accelerated innovation. "We'll see how we can build these new models going forward while protecting scientific integrity," she says, in terms of building a resilient 21 st century research university.

The Workshop participants raised numerous visions, such as a university system that rewards teaching on the same level that it rewards research; a career path that thrives on diversity, equity, and inclusion; international collaboration and cooperation; government funding; and a system that ensures trust from the general public. 


\section{Wake-up call}

Trustworthiness of the research enterprise is particularly on shaky ground as one outcome of the COVID-19 pandemic. As of July 20, 482 therapeutic agents and 156 vaccine studies are in the pipeline, says Christine Grady, Chief of Bioethics and Head of the Section on Human Subjects Research at the National Institutes of Health (NIH), speaking at the NAS Workshop in July. An ethical concern, she says, is how to expedite COVID-19 research without sacrificing rigor.

One of the vaccine studies that went into the Phase III trial in the summer is mRNA-1273, the basis for Moderna, Inc.'s lipid nanoparticle-based Covid vaccine (see MRS Bulletin doi:10.1557/ mrs.2020.154). Robert Langer, cofounder of the company, told $M R S$ Bulletin that Moderna has published numerous peer-review papers with journals such as Nature Communications and went through a vigorous review process with the FDA. The company Moderna has also published results in The New England Journal of Medicine, he said. This is a high-impact (74.699) medical journal with vigorous peer-, statistical-, and editorial review processes. The latest article reported results on the Phase I clinical study of its vaccine against COVID-19.

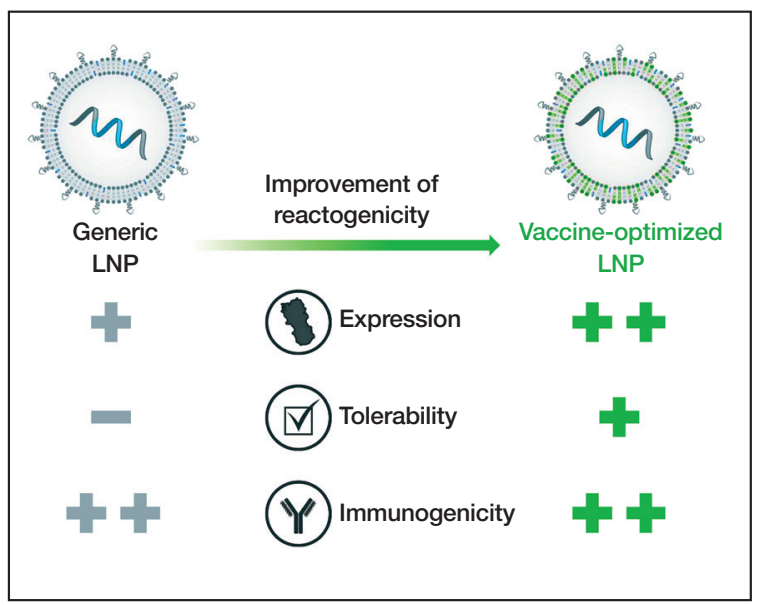

Moderna's proprietary lipid nanoparticle (LNP) vaccine formulation is optimized to produce more protein (enhanced expression), have fewer injection site reactions (increased tolerability), and lead to production of a more robust immune response (greater immunogenicity) than the industry standard LNP formulation. Credit: Moderna, Inc.
Alana Ogata, a postdoctoral research fellow at Brigham and Women's Hospital in David Walt's group, accounts for the acceleration in COVID-19 research from her participation in the newly formed Massachusetts Consortium on Pathogen Readiness (MassCPR). With the onset of the pandemic, MassCPR quickly gathered researchers, doctors, and clinicians from the numerous research hospitals and university laboratories in the Greater Boston area in order to share resources and frequent updates on their progress. "One reason our research was successful, I think, is because we had access to really highquality protein and antibody products from our collaborators," says Ogata, who was developing diagnostic tests for COVID-19.

"Almost immediately we had a collaborator who had a very high-quality COVID-192-spike protein we were able to use. Then we reached out to other collaborators at Dana-Farber Cancer Institute who had certain antibodies and they were more than happy to give us some. Creating new collaborations was easy and seamless," Ogata says. The Walt group has developed ultrasensitive single-molecule array (SIMOA) assays they now use for studying SARS-CoV-2 antibodies and antigens in order to study the response of the immune system over time. As the inventor of the SIMOA technology, Walt has founded the company Quanterix Corporation which is developing an ultrasensitive digital immunoassay platform. According to Grady, the pandemic has forced research universities to set priorities, such as what ideas are "useable" in the fight against the disease and what ideas the laboratory has the capacity to pursue. While research groups may be vying to come out with the first vaccine, they need partnerships in order to pool resources, she says. The MassCPR illustrates such a partnership.
The pandemic also brings to light the significance of international cooperation and collaboration as research laboratories all over the world race to develop a vaccine as well as other solutions to curb the spread of COVID-19, from makeshift 3D printing of ventilators to microfluidic devices for treatment to anti-viral coatings for masks as well as counter surfaces (see MRS Bulletin, doi:10.1557/mrs.2020.183). At the NAS Workshop, Arthur Bienenstock, Professor Emeritus of Photon Science and Special Assistant to the President for Federal Research Policy at Stanford University, says the economic fallout from the pandemic can go one of two ways. Either the amount of international collaboration will decrease due to a decline in science funding or it will increase because the decline in funding will make shared research facilities more of a necessity.

Referring to the large hadron collider as an example, Bienenstock says it will cost a little under $\$ 5$ billion to construct, then a little over $\$ 1$ billion to operate. For financial resources and expertise, he says, international collaboration is important. Yet, with barriers to travel, how can such complex systems be assembled when the various components are fabricated in different countries, he asks.

Just as the Internet enables virtual conferences, Bienenstock says, "We may even develop remote capabilities to guide local staff in the installation, operation, and maintenance of extremely complex instrumentation."

Another long-lasting funding issue exacerbated by the pandemic is that of state-funded universities. Julia Phillips, retired from Sandia National Laboratories and chair of the American Institute of Physics (AIP) Panel on the COVID19 Pandemic's Impact on the Physical Sciences Enterprise, told MRS Bulletin that "the question is to how many will even survive this." According to the report the panel published, Peril and Promise, "Many institutions, particularly state universities, which are the source of a majority of physical science and engineering majors...have suffered from years of steadily decreasing state support... and rely heavily on revenue from room and board and from international students, sources of 
income that have been severely cut if not eliminated as a result of the pandemic."

Phillips points to the science and engineering indicators published by the National Science Board in January that reports close to $60 \%$ of engineers in the US with $\mathrm{PhD}$ degrees were born outside the country. "It is awesome to be attracting the best and the brightest from around the world," Phillips says; "I question how long that is going to continue." And she finds this particularly concerning because not enough US students are currently driven to study in the physical sciences.

According to a survey taken from April 29 to May 5, 2020, the Pew Research Center reported that $52 \%$ of Americans believe the US has done a fair or poor job of handling the COVID-19 outbreak. Of these, around "two-thirds of those under $30(65 \%)$ say the U.S. has done a poor job, compared with $59 \%$ of those ages 30 to 49 and only around four-in-ten of those 50 and older." Among minority communities, the survey found that "Black $(63 \%)$ and Hispanic (57\%) Americans also rate the US response more negatively than white, non-Hispanic Americans (48\%)." What this means for science, Grady says, is that the research process should be transparent and should engage the public.

The call to engage the public reiterates comments made in the February symposium where participants advocated for a patient-centric research system and for building up a more diverse and inclusive research community (see MRS Bulletin doi:10.1557/mrs.2020.154). At the earlier symposium, Cristin Dorgelo, president and CEO of the Association of Science and Technology Centers and former chief of staff at the White House Office of Science and Technology Policy during the Obama administration, described the public-engagement process undertaken for the US Brain Initiative-which is aimed at revolutionizing scientific understanding of the human brain. Researchers explained their 10 -year R\&D agenda to the public, which has a stake in curing diseases, she said.

Also in the February symposium, Shobita Parthasarathy, professor of public policy at the University of Michigan, expounded on "segments of the com-

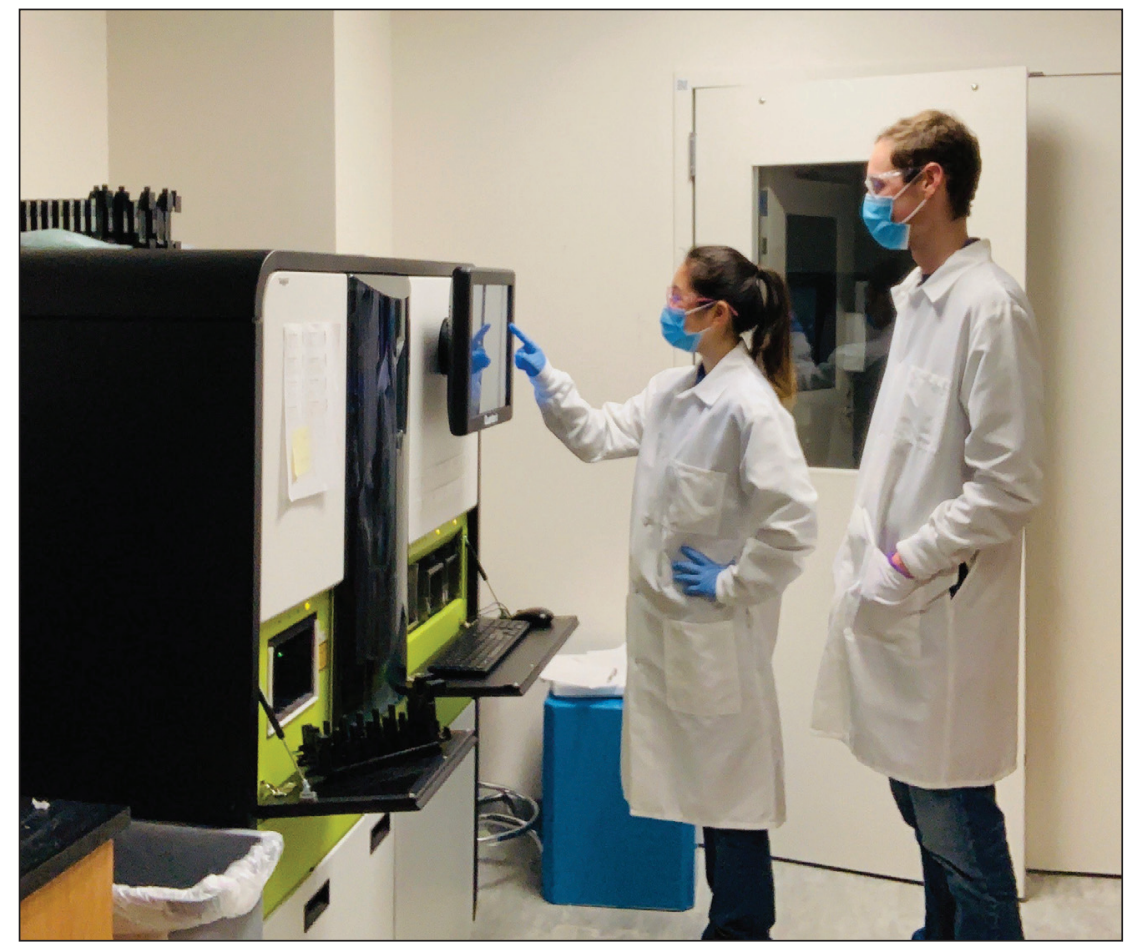

Alana Ogata (left) with laboratory partner Adam Maley at the Quanterix HD-X instrument where they run their SIMOA tests. Four researchers worked in pairs in the laboratory, rotating shifts. The laboratory is at Brigham and Women's Hospital in Boston, where the researchers work in David Walt's group, who has appointments with Brigham and Women's Hospital, Harvard Medical School, and the Wyss Institute. Credit: Alana Ogata.

munity [who] have been marginalized," and the importance of including social context when designing research plans. The inclusion of the broad diversity of the community both in the planning stages and as scientific researchers themselves continues as a high priority in the July Workshop.

The fallout from the pandemic poses particular problems for women and racial and ethnic minorities. Geraldine Richmond, Presidential Chair in Science and Professor of Chemistry at the University of Oregon, says, "The retention rate is lower for women than it is for men and incredibly horrible for a percentage of students including African Americans. With the global issues we face, we cannot afford to leave any talent behind so we have to work harder at this."

A common thread during the NAS Workshop were discussions about maintaining the pipeline in the physical sciences in light of the pandemic. Mary Sue Coleman, President of the Association of American Universities, said early-career researchers are missing opportunities for competitive positions because of cutbacks, for example, in fellowship programs. To adapt to the pandemic, many laboratories are functioning with split schedules for on-site research activities; but these are particularly difficult for matching women's needs, she says.

According to the Society of Women Engineers (SWE), "More than half of [the SWE survey] respondents in the workforce report that COVID-19 has negatively impacted their personal opportunities and interpersonal relationships with professional colleagues." The survey taken in July, on the "Impact of COVID-19 on Women in Engineering and Technology," reports that $24 \%$ of students who graduated in the Spring had their job offers postponed or rescinded. While nearly half of the students surveyed are concerned about a delay in their graduation, this concerns students of color (57\%) to a greater extent than white students (41\%). Furthermore, the survey finds, "while childcare responsibilities were often shared equally with 
their partners, respondents were more often tasked with educational support for their children and caring for adult dependents during COVID-19," and students of color are disproportionately affected by the increase in household chores (see Table I). This status dilutes the effort they can put into their research, Phillips says.

\section{Risk for materials research}

In March, many students returned to their colleges and universities from Spring break to discover within a week that classes had been moved online and laboratories had been shut down. "This was my last semester at the University of Florida, and research was my priority of the semester because it contributed to my honors thesis and was the final wrap-up of my project," says Tran Ngo, an undergraduate student in biomaterials. "Everything about undergraduate research was put at a pause a week after the first case found in Gainesville, Florida," she says.

Such stories reverberated across the country. Chiung-Wei Huang, a graduate student at the University of North Carolina at Chapel Hill, combines spectroscopy with scanning probe microscopy to study molecular structures that illuminate chemical reactions at the surfaces and interfaces of materials. She says $80 \%$ of her work

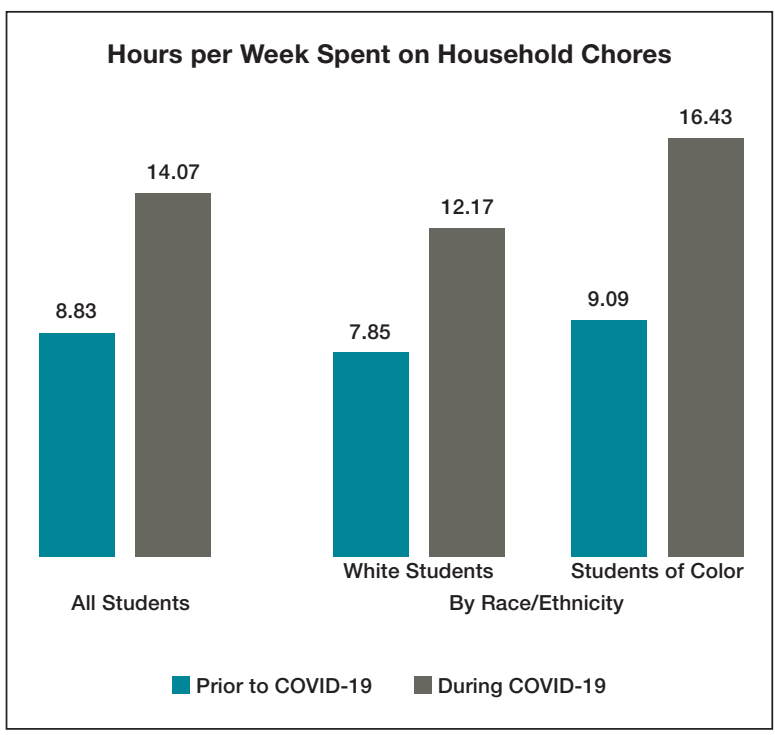

Table I. From the Society of Women Engineers, Impact of COVID-19 on Women in Engineering and Technology, September 2020. was on-site in the laboratory using the instruments. She is in her last year where she planned to do more electrochemical Raman spectroscopy study of materials. "When the pandemic hit I literally just shifted to computation," she says. Huang's former labmate had collected hyperspectral data that needed to be interpreted. Because Huang has prior experience with computation and an interest in learning more programming, she is analyzing the data and preparing a manuscript.

Likewise Edan Alpern, who completed his undergraduate work this year at the University of Pittsburgh, transitioned from laboratory work in Jeremy Levy's group on quantum materials to computational work for Levy's collaborator Eli Zeldov at the Weizmann Institute of Science in Israel. Alpern has been accepted at Weizmann for graduate studies, but remains in the US due to the pandemic. In the laboratory, Alpern's job was to set up the experiments. "My experience was very hands-on educational," he says. "Now it's entirely programming. I'm basically setting up an infrastructure of code to allow us to more smoothly run the experiments at the Weizmann Institute when I eventually get there."

Early-career materials researchers have also experienced special difficulties. Monica Jung de Andrade, who is currently a research scientist at the Alan G. MacDiarmid NanoTech Institute and an instructor at The University of Texas at Dallas, was in the midst of interviews for a professorship, but some of the positions have since been cancelled. "Noticing that the job market for someone with my skills seems stagnated, I stopped looking for a new position," says de Andrade, who focuses her research on smart nanostructured fibers and yarns. "Instead,
I'm looking for secondary jobs to supplement my income." In the meantime, de Andrade is able to access her laboratory where she conducts all the experiments herself in order to learn new things in her current position. To help her students who are interested in research but unable to access the laboratory, de Andrade creates simple online tasks.

At the NAS Workshop, Suzanne Ortega, President of the Council of Graduate Schools, brought up numerous questions in light of the pandemic. For the Fall semester, she says, universities need to review how to assist in professional development for a rapidly transforming workforce. In converting internships with private companies into a virtual experience, how will students be aided in understanding the corporate network? How will funding and timing for the degree be modified to account for work away from the laboratory? How does the university "convert a high-touch model to a high-virtual model?" she asks.

Solutions to these questions may be critical to sustain a generation of students in the physical sciences. "When Sputnik went up, we all read books like Rocket Boys. We were really influenced by Sputnik and the emphasis on science education. The emphasis was really on the physical sciences," Phillips told MRS Bulletin. The pandemic, she expects, will draw science-interested students to the biological and medical fields. And with the switch to online classes in their junior and senior year of high school, students are missing the laboratory experience that would expose them to the role physical sciences - and materials research in particular - can play to resolve the pandemic.

As a member of the AIP TEAM-UP Task Force that recently released the report The Time is Now: Systemic Changes to Increase African Americans with Bachelor's Degrees in Physics and Astronomy, Dobbins is also concerned about the impact of the pandemic on students in the physical sciences. To help students increase their identity with the physical sciences, she says, colleges and universities need to make summer research opportunities available to their undergraduate students. "It provides the students with the one-on-one 
mentorship that gives them the ability to excel at solving problems outside of the classroom. It gives them that feedback into their confidence," she says.

Ngo agrees. "In-person lab experience is the main reason why I want to pursue biomaterials research for medical applications," she says. "In-person lab experience gives the soul to the knowledge that we learn from textbooks because we actually use the information, interact with it, and troubleshoot."

Ngo takes it a step further. As a firstgeneration college student accepted into the McNair Scholars Program at the University of Florida, Ngo benefits from the program designed to give undergraduate students from disadvantaged backgrounds the resources they need to pursue a $\mathrm{PhD}$ degree (see MRS Bulletin, doi:10.1557/ mrs.2015.132). Ngo says the Program provides professional development such as how to write research papers, tailor personal statements for applications, and create presentations. The program also provided travel funds so $\mathrm{Ngo}$ could present a poster at the Biomedical Engineering Society Conference a year ago where she met the Principal Investigator who offered her a postbaccalaureate training fellowship at the $\mathrm{NIH}$, beginning this Fall. Ngo will study biomaterials used in immunoengineering applications for the next two years.

While high school prepared Ngo to learn about science from textbooks and science fairs, it did not induce her interest in scientific research, she says. When she was accepted into a research group during her first semester at the university, she began to gain more understanding on how to conduct scientific research outside of her course hours under the mentorship of a graduate student and learned to work in a collaborative research environment. "Within the undergraduate work related to their lab work, I was trying to find extracellular matrix-derived materials to mimic nerve tissue," Ngo says.

However, not all students have fared as well. Patricia Stampe, Professor of Physics at Florida Agricultural \& Mechanical University (FAMU), told MRS Bulletin that after closing down research laboratories in April, the

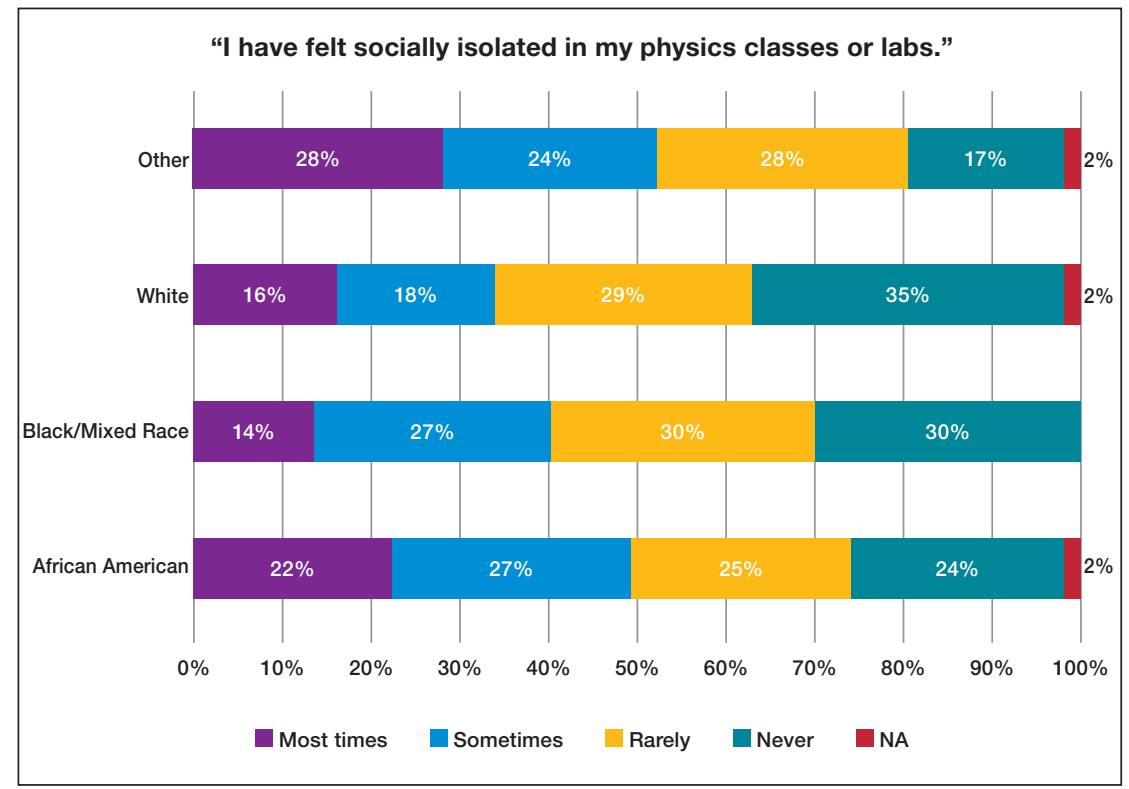

Students' sense of isolation in physics classes or laboratories by race. From American Institute of Physics TEAM-UP report, The Time is Now: Systemic Changes to Increase African Americans with Bachelor's Degrees in Physics and Astronomy, 2020.

university began letting graduate students return in August. "However, my grad student has a young child, and will not be able to return until daycare facilities reopen," Stampe says. She has one graduate student, and she was about one month from finishing data collection when the university closed.

"Specifically, for my student, [the pandemic] has probably put her back by some months for graduating," Stampe says. Along with trying to work from home while taking care of a young child, Stampe's student had some computer issues. "It also slows things down when there is not the capability for her to just walk up to me and ask me about how to do a certain bit of analysis, or to explain some equipment etc., and things have to be done electronically," Stampe says.

Stampe also described, at FAMU, a student environment similar to the one Ngo described. "[At] HBCUs [Historically Black Colleges and Universities] we often have a more nontraditional cross section of graduate students who may be unprepared for the rigorous requirements of research and graduate school. I don't necessarily mean academically, but more in terms of not having exposure to and thus an understanding of what is required in terms of time spent in the lab, and dedication to research." Now the pandemic further exacerbates their career trajectory.

Pointing to early-career faculty members, Stampe says, "The [FAMU] faculty union has negotiated with the administration for an additional year toward tenure for tenure-earning faculty. Other faculty are trying to use the time to write publications and grant proposals, but those with young children have other demands on their time."

Completing their last year or two as a graduate student and postdoc, respectively, Huang and Ogata are now reconsidering their career plans since a number of universities and industries have a hiring freeze. Whereas Huang initially thought about returning to industry, her main interest is in science writing which particularly flourished during the shutdown. She is considering an online business in science communications and consultation.

Ogata initially set out applying for a faculty position, believing she had two years to try. Not knowing when the general hiring freeze will lift, however, she says, "I would start seeing how my skills could be honed for going into industry." Ogata says some of her colleagues are also looking into backup plans. 
DeAndrade is taking this time to reflect on how to improve society and the general mind-set. For example, she says, "How can we enable inclusion in society? Are we valuing our scientists who are daily exposing themselves to unknown substances for the advancement of knowledge?" De Andrade is attending free online webinars and intensifying her connection with her home country, Brazil, by contributing to professional associations there in addition to serving on the Board of Directors for the Materials Research Society.

On a more dire note, the SWE survey finds that $37 \%$ of their respondents are concerned about losing their jobs by the end of the year.

\section{Going forward}

At the NAS Workshop, Coleman asked, "What should the laboratory design look like in the future because this is not the only pandemic that we are going to face? We are in a new era."

This new era should embrace international work, said a number of panelists. "In the international realm, it's time for the research universities to rethink standards that go beyond simplistic metrics like the number of publications and citations," Richmond says. "[Universities should] recognize the importance of faculty that work internationally and globally on urgent projects and to give value to this." Richmond acknowledges that the impact, however, "is less easy to quantify in the near term." Just as researchers have demonstrated the importance of international collaboration and cooperation to resolve the pandemic, "the same can be [done] for climate change," Richmond says.

AIP also recommends placing high priority on topics of international concern."[T] he pandemic may cause a significant jump in students interested in studying biology and medicine," AIP publishes in its report Peril and Promise; "A parallel increase in the number interested in the physical sciences could occur if there is high-quality instruction and if the case is made strongly that physical sciences advances are critical to addressing crises of all kinds, including those of a medical nature."

While Phillips, who chaired the panel that published Peril and Promise,

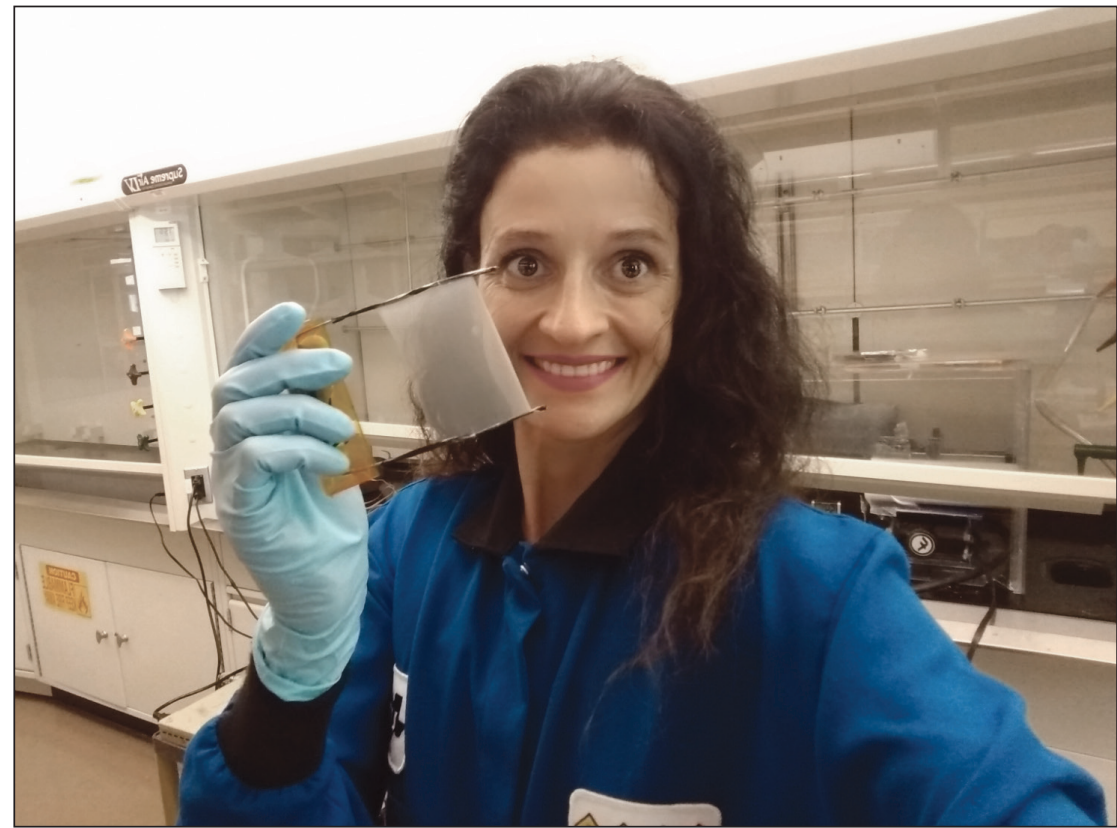

Monica Jung de Andrade, research scientist at the Alan G. MacDiarmid NanoTech Institute and an instructor at The University of Texas at Dallas, holds a sheet of aligned polymeric nanofibers she prepared by electrospinning. Credit: Monica Jung de Andrade.

expresses concern about losing half a generation from the physical sciences, she also sees opportunities to recapture interest. If the country resolves the issue of Internet access not only to close the wealth gap but also geography gap considering that students in many rural areas lack reliable Internet access, the Internet can be leveraged to bring museums, universities, and laboratories into the homes and schools of the science-interested public. Webinars and seminars can also inform students and the general population about materials research.

"If I were asked to do something, say, for a tribal college out in Shiprock, New Mexico, I could do it now as opposed to having to figure out how I can travel to Shiprock," Phillips says. "It is an opportunity for underserved communities to engage with researchers in a way that was probably impossible to imagine previously."

With the frequent use of online meetings, materials researchers are also experiencing a segue into a new research culture. "Because of the Zoom and the WebEx platform, people from across the world can now have interdisciplinary detailed talks and discussions on a weekly basis. I think that is just fantastic; I don't know why we weren't doing it before," Dobbins says.

Phillips says, "I am absolutely ecstatic that I don't have to travel every other week because, from where I live, that is a huge deal. I have been in all the meetings I have been supposed to be in virtually." While acknowledging that online meetings lose some important advantages of on-site meetings, "it establishes that not every interaction has to be face-to-face," she says.

The experience of the pandemic has also taught other lessons that can be folded into a new research culture. Because of limited time in the laboratory, Huang discovered ways to further think about her research and more carefully plan her experiments, in addition to communicating more closely with her collaborators because "I'll have one shot to do [the experiment]." Before the university shutdown, $\mathrm{PhD}$ students would tend to feel guilty for any time spent away from the laboratory, she says. Now Huang hopes the research community understands that time away from the laboratory can be productive.

In the US research university system of the 21 st century, Ogata sees value in pulling together collaborations such as seen with MassCPR. Experts in various fields 
could quickly receive the resources they need and quickly share the results of their studies so that other experts can then concentrate on their component of the project on-hand.

Ogata's experience reinforces the findings of the AIP report Peril and Promise that talks about "convergence research," whereby knowledge, methods, and expertise from researchers in different fields work together. "The scientific enterprise has been trending toward more inter- and transdisciplinary research over the years. The pandemic may accelerate that trend," the AIP panel reports.

De Andrade sees a post-pandemic situation that will facilitate a humanistic view toward science and more diverse collaborations with other countries. "For instance, while some countries/institutions are still in lockdown, collaborators who are not in lockdown have been doing experiments for their collaborator colleagues. Later, those experiments will be replicated and continued at those countries/institutions which are under lockdown at the moment," de Andrade tells MRS Bulletin. "I believe our research institutions need to be more diverse both in topics, as well as collaboration. This will help avoid interruptions or slowdown in research," she says.

One solution to drive diversity, equity, and inclusion into the US research universities of the 21 st century is for the government to equitably fund HBCUs. Stampe says, "HBCUs can be more challenging due to the typically higher teaching loads for faculty members, and generally less facilities and startup funds available." When she was hired in 1998, Stampe received no startup funds. "However, our last few faculty hires have been given access to some startup funds for equipment purchase, and in general are getting a reduced teaching load compared to other faculty, so things are slowly improving," she says.

Materials research laboratories, she says, depend heavily on access to expensive, large pieces of equipment, such as electron microscopes and x-ray sources, as well as access to cryogens. "This means funding for staff and maintenance, which can be hard to wangle," she says.

A summer meeting of the National Science Board (NSB) - which establishes the policies for the US National Science Foundation - focused its attention on HBCUs in its panel discussion, "Framing Black Experiences in Science and Engineering." In May 2020, NSB released a report on Vision 2030, in which the board expresses the need for the science and engineering (S\&E) workforce to be representative of the US population in 2030. This means that the number of African American scientists and engineers must more than double. Panelist William Jackson, Emeritus professor of chemistry at the University of California-Davis (UC Davis) and previously professor of chemistry and physics at Howard University, tells NSB, "You have a daunting task to raise the number of active participants in the science and engineering enterprise in 10 years by a factor of roughly three rather than what you've done in the past 50 years, a factor of two, from $2 \%$ to maybe $4 \%$, depending on how you calculate it."

Describing the success of Howard University which, according to Jackson, should have been in the top 10 universities of the country, Jackson says, "This is a university that is directly funded by the federal government. When you compare it to UC Davis when they had roughly the same number of students - 12,000 for Howard University, 14,000 for UC Davis - the funding for UC Davis was twice that of Howard University. And it was actually worse than that since capital costs at UC campus are not considered in their basic budget. Thus Howard University was being asked to do the same kind of job UC Davis was doing on less than $50 \%$ on the dollar."

Edan Alpern sees another systemic failure of the US university system. He told MRS Bulletin that the university is set up to identify the so-called "good students" who can get A's in their classes and is much less about training students to have the necessary skills. For example, he says, his level of high-school courses in math and physics together with additional math classes he took at the university prepared him for the undergraduate course on electricity and magnetism, whereas students without the same background left the course with "holes" in their knowledge that propagates to the next course and the next.

"I think that more needs to be done to identify students who are interested in these fields," Alpern says, "and if they are not the most prepared, then fund them for a year or two of supplementary training in between high school and college classes. That way they have a solid foundation on which they can build."

Dobbins reinforces the idea of systemic changes. She says, "A lone champion helping low income or the underrepresented minority students is a model that we appreciate but we also should discourage it as a whole. We want the entire infrastructure to be supportive."

Alpern says, "We are wasting a tremendous amount of human capital by not giving the [unprepared student] the attention and support that they deserve."

What would help the university system understand what students and earlycareer researchers need? "The whole process of really supporting - whether it's supporting the junior faculty or students," Dobbins says, "is to be able to listen to their lived experience."

"We need a new mind-set toward science, people, and diversity," says de Andrade. "We all depend on each other to purposefully advance science in a more humanistic society."

Judy Meiksin

We welcome comments and feedback on this article via email to Bulletin@mrs.org.

\section{mrs.org/covid-19-resources}

